\title{
High-frequency deregulated expression of Wnt signaling pathway members in breast carcinomas
}

This article was published in the following Dove Press journal:

OncoTargets and Therapy

\author{
Zahid Khan' \\ Maha Arafah ${ }^{2}$ \\ Jilani Purusottapatnam \\ Shaik' \\ Alka Mahale \\ Mohammad Saud Alanazi' \\ 'Genome Research Chair, Department \\ of Biochemistry, College of Science, \\ King Saud University, Riyadh, \\ ${ }^{2}$ Department of Pathology, College \\ of Medicine, King Saud University, \\ Riyadh, ${ }^{3}$ King Khaled Eye Specialist \\ Hospital, Riyadh, Kingdom of Saudi \\ Arabia
}

Purpose: Breast carcinoma is the most common malignancy and leading cause of cancer-related deaths in women worldwide including Saudi Arabia. Breast cancer in Saudi women develops at a much early age with median age of onset of 49 years compared to 62 years observed in patients from USA. Aberrations in wingless and integration site growth factor (Wnt) signaling pathway have been pathologically implicated in development of breast cancers and hence its role was examined in Saudi patients.

Materials and methods: We immunohistochemically examined various components of Wnt signaling pathway including $\beta$-catenin, tumor suppressor proteins, adenomatous polyposis coli (APC), and Axin, expression of naturally occurring pathway antagonists such as Dickkopf Wnt signaling pathway inhibitor 3 (DKK3), FRP2, and WIF1, as well as Wnt target cyclin D1 and c-Myc to establish if the pathway is constitutively activated in breast cancers arising in Saudi women.

Results: Cytoplasmic $\beta$-catenin, indicative of activation of the pathway, was observed in $24 \%$ of cases. Expression of APC and Axin, which are components of $\beta$-catenin destruction complex, was lost in 5\% and 10\% of tumors, respectively. Additionally, Wnt signaling inhibitors DKK3, FRP2, and Wnt inhibitory factor 1 (WIF1) were not expressed in $8 \%, 14 \%$, and $5 \%$ breast tumors, respectively. Overall, accumulation of cytoplasmic $\beta$-catenin and downregulation of other Wnt pathway proteins (APC/Axin/DKK3/FRP2/WIF1) were found in approximately half of the breast cancers (47\%) in our cohort. Consistent with this, analysis of Wnt target genes demonstrated moderate-to-strong expression of c-Myc in 58\% and cyclin D1 in 50\% of breast cancers. Deregulation of Wnt pathway was not associated with age of onset of the disease, tumor grade, and triple-negative status of breast cancers.

Conclusions: High level of deregulated expression of Wnt pathway proteins suggests its important role in pathogenesis of breast cancers arising in Saudi women who may benefit from development of therapeutic drugs targeting this pathway.

Keywords: breast cancer, Wnt signaling pathway, immunohistochemistry, $\beta$-catenin

\section{Introduction}

Breast cancer is the most common malignancy among women with an annual worldwide incidence of about 1.67 million in $2012 .{ }^{1}$ Majority of breast tumors originate as a result of transformation of ductal epithelial cells and are thought to have progressed through a linear stepwise clinically and pathologically defined stages. Genetic and epigenetic alterations in ductal epithelial cells lead to initiation of premalignant atypical ductal hyperplasia, which by further accumulating molecular changes progresses to noninvasive ductal carcinoma (IDC) in situ with a potential to develop into IDC leading to metastasis., ${ }^{2,3}$ As in the western countries, breast cancer is the leading malignancy, comprising about $27 \%$ of all malignancies in Saudi women. ${ }^{4}$ However, contrary to
Correspondence: Zahid Khan

Genome Research Chair, Departmen of Biochemistry, College of Science, King Saud University, Riyadh I I45I, Kingdom of Saudi Arabia

Tel+966 II 4675802

Email zkhan@ksu.edu.sa 
that seen in western women, breast cancer in Saudi women develops at a much early age. In Saudi Arabian patients, about a quarter of the breast cancers developed before the age of 40 , which is significantly higher compared to $6.5 \%$ in the USA. ${ }^{5}$ A probable cause for the early onset in the Saudi females could be due to considerable molecular differences and variations in the associated environmental factors between the two ethnic groups. Carcinoma of breast in younger women is frequently associated with more aggressive disease, poorer prognosis, and decreased 5-year survival., ${ }^{6,7}$ Current breast cancer treatment predominantly depends on the status of estrogen receptor (ER), progesterone receptor (PR), and human epidermal growth factor receptor 2 (HER2). Tumors expressing either one or both of the hormone receptors can be targeted with endocrine therapies, while patients with HER2-overexpressing tumors are treated with anti-HER2 agents such as monoclonal antibodies. Tumors showing absence of hormone receptors and lack of overexpression of HER2 are classified as triple-negative breast cancer (TNBC) that requires nonspecific and highly toxic chemotherapy regimens. Despite improvement in survival outcomes owing to advances in treatment of endocrine-dependent and HER2overexpressing tumors as well as due to breast-screening programs, complete understanding of molecular mechanism of transformation is still unclear. However, it is observed that a variety of genetic lesions and epigenetic modifications are present in human breast neoplasms. Deregulation of several signaling pathways has been implicated with breast cancer development including the wingless and integration site growth factor (Wnt) pathway. Signaling by Wnt family glycoproteins controls critical processes such as cell fate determination, cell proliferation, and migration during embryonic development and tissue homeostasis in adult organisms. ${ }^{8} \mathrm{Wnt}$ pathway regulates proliferation and self-renewal of intestinal and skin epithelial stem cells and plays crucial roles in gastrointestinal and skin homeostasis. ${ }^{9-11}$ There is strong evidence for involvement of Wnt pathway at several stages of mouse mammary gland development. ${ }^{12}$ In the absence of Wnt ligand stimulation or the "off state", $\beta$-catenin is phosphorylated by casein kinase 1 and glycogen synthase kinase- $\beta$ (GSK3 $\beta$ ) creating a binding site for E3 ubiquitin ligase $\beta$-Trcp, leading to degradation through ubiquitination pathway. ${ }^{13}$ In the "on state", inhibition of this phosphorylation results in accumulation of uncomplexed cytosolic $\beta$-catenin that translocates to the nucleus and partners with T-cell factor/ lymphoid enhancer factor (TCF/LEF) family of proteins to transcribe Wnt target genes such as $c$-myc and cyclin D1 leading to tumorigenesis. ${ }^{14,15}$ Thus, detection of nuclear and/ or cytoplasmic $\beta$-catenin is indicative of activation of Wnt signaling cascade. Activated Wnt signaling pathway has been demonstrated in mouse mammary tumorigenesis model. ${ }^{16,17}$ Moreover, constitutively activated Wnt signaling has been shown to be causally involved in several different types of human cancers. ${ }^{18,19}$ Genetic mutations of certain components of this pathway, such as adenomatous polyposis coli (APC) and $\beta$-catenin, are important early events in colorectal carcinogenesis, and they are rarely associated with breast malignancies. ${ }^{20-23}$ However, data from numerous studies suggest that this pathway is deregulated in breast cancer probably through other mechanisms. ${ }^{24-27}$ Elevated levels of nuclear and/ or cytoplasmic $\beta$-catenin, a critical downstream component of Wnt signaling pathway and a hallmark of pathway activation, have been observed in human breast cancers. ${ }^{26,28}$ Aberrant Wnt activation is found in $40 \%-60 \%$ of breast cancers. ${ }^{29}$ Thus, sufficient evidence points to the involvement of Wnt signaling pathway in breast cancers, and hence the current study was undertaken to investigate this pathway in Saudi Arabian patients. We examined various components of the pathway such as transcriptional coactivator $\beta$-catenin; tumor suppressors and components of $\beta$-catenin destruction complex APC and Axin; naturally occurring inhibitors of Wnt signaling Dickkopf 3 (DKK3), secreted frizzled-related protein 2 (SFRP2 or FRP2), and Wnt inhibitory factor 1 (WIF1) along with Wnt pathway target genes cyclin D1 and c-Myc.

\section{Materials and methods Patient samples}

Sixty-nine archival formalin-fixed paraffin-embedded (FFPE) blocks prepared from breast cancer tissues collected between 2012 and 2014 were retrieved from the pathology department of King Khalid University Hospital (KKUH), Riyadh for construction of tissue microarray (TMA). The study samples were anonymized for patient confidentiality. None of the patients received chemotherapy or radiotherapy before obtaining the tissue samples.

\section{Ethics statement}

The study was conducted in accordance with the Declaration of Helsinki, and approved by the Ethics Committee of KKUH as per reference number 14/4322/IRB, without the requirement for consent to participate because of the use of archival anonymized samples.

\section{TMA blocks preparation and immunohistochemistry (IHC)}

The region of interest on the donor block was identified after reviewing the hematoxylin-and-eosin-stained sections. Tissue cores were punched in the identified region containing 
tumor cells in each donor block using $2 \mathrm{~mm}$ biopsy punch (Miltex, Germany). Selected cores were transferred into a recipient paraffin wax block. Resulting TMA blocks were placed upside down onto a glass slide and warmed in an oven at $37^{\circ} \mathrm{C}-40^{\circ} \mathrm{C}$ overnight. TMA blocks were kept in a refrigerator to cool, after which the glass slide was detached. Four-micrometer sections were cut using rotary microtome (Leica RM 2235). Sections floating on a water bath at $45^{\circ} \mathrm{C}$ were mounted on silane-coated glass slides that were incubated at $60^{\circ} \mathrm{C}$ for 15 minutes in a hot air oven.

Immunohistochemical staining was performed on BenchMark XT automated slide stainer (Ventana Medical Systems, AZ, USA). Deparaffinization of tissue sections was carried out with EZ Prep solution (Ventana Medical Systems) for 4 minutes followed by three washes with EZ Prep solution. Antigen retrieval was performed in cell conditioning solution $(\mathrm{CC} 1)$ at $100^{\circ} \mathrm{C}$ for 36 minutes. Sections were incubated with UV inhibitor (Ventana Medical Systems) for 4 minutes at $37^{\circ} \mathrm{C}$ for blocking endogenous peroxidase. Slides were incubated at $37^{\circ} \mathrm{C}$ for 32 minutes with the following primary antibodies: $\beta$-catenin, 1:250 diluted (BD Transduction Laboratories); APC (C-20), 1:100 diluted (Santa Cruz Biotechnology); Axin (H-98), 1:100 diluted (Santa Cruz Biotechnology); DKK3, 1:100 diluted (Abgent); FRP-2 (H-140), 1:100 diluted (Santa Cruz Biotechnology); WIF1, 1:100 diluted (R\&D Systems); c-Myc (9E10), 1:50 diluted (Santa Cruz Biotechnology); Cyclin D1 (A-12), 1:100 diluted (Santa Cruz Biotechnology). Specific staining of the target molecules was determined by replacing the primary antibody with phosphate-buffered saline in the negative controls. Tissue sections were then incubated in ultraview horseradish peroxidase Universal Multimer (Ventana Medical Systems) for 8 minutes at $37^{\circ} \mathrm{C}$. Visualization of the antigen was performed by adding UV 3,3'-diaminobenzidine (DAB) and UV DAB H2O2 (Ventana Medical Systems) at room temperature for 8 minutes. Enhancement of DAB chromogen was performed by UV Copper (Ventana Medical Systems) for 4 minutes at room temperature. Nuclear counterstaining was carried out by incubating tissue sections in hematoxylin II (Ventana Medical Systems) for 8 minutes followed by incubation in Bluing Reagent (Ventana Medical Systems) for 4 minutes. Liquid coverslips (LCS) from Ventana Medical Systems were applied between the aqueous reagents and air to prevent evaporation. Upon completion of the run, slides were removed from the automated slide stainer and washed in a mild dishwashing detergent to remove the LCS solution. Tissue sections were dehydrated by sequentially passing through 70\% ethanol, 96\% ethanol, absolute ethanol, and two changes in xylene. Immunostained sections were cover-slipped using DPX mounting media and visualized under Olympus BX51 light microscope. Micrographs were captured by DP72 Olympus digital camera using 20× objective lens and CellSens software.

\section{Immunohistochemical scoring}

Analysis and scoring for each antibody staining were completed by the senior pathologist, Dr Maha Arafah, Associate professor, KKUH, Riyadh. Tumors were assessed for both intensity and proportion of cells showing positive staining. Staining intensity in malignant cells was scored as $0,1+$, $2+$, or $3+$ corresponding to the presence of negative, weak, moderate, and strong brown staining, respectively. Scores for the proportion of malignant cells staining positively were assigned as $1=0 \%-4 \% ; 2=5 \%-19 \% ; 3=20 \%-39 \%$; $4=40 \%-59 \% ; 5=60 \%-79 \% ; 6=80 \%-100 \%{ }^{30}$ As majority of the cases exhibited uniform positivity in $100 \%$ of the malignant cells, only staining intensity was considered.

\section{Statistical analysis}

Fisher's exact test was performed to study the association of Wnt pathway activation with clinicopathological parameters such as age of onset of breast cancer, tumor grade, and receptor status as triple-negative versus non-triple-negative breast cancer. Spearman's rank correlation coefficient (r) analysis was performed using web-based software http://www. socscistatistics.com/tests/spearman/Default.aspx. $P<0.05$ was considered as a statistically significant difference.

\section{Results \\ Clinicopathological characteristics of breast cancer cases}

In total, 69 histologically confirmed breast cancer cases were analyzed by IHC for expression of Wnt signaling pathway proteins. Median age of patients was 50 years with age ranging from 26 to 88 years. Majority of the breast cancer histological types were IDCs $(n=62)$, while seven cases were diagnosed as lobular type. Pathological grades of the tumors were as follows: Grade 1, n=8; Grade 2, n=38; Grade 3, n=23. Hormone receptor expression analyses showed that ERs were present in $55(80 \%)$ cases while PRs were expressed in $49(71 \%)$ of the cases. HER2 overexpression was seen in $8(12 \%)$ breast cancers. TNBC that does not express ER, PR, and HER2 was found to be $17 \%(n=12)$ in our breast cancer cohort.

\section{Expression of $\beta$-catenin destruction complex components}

We examined expression and localization of $\beta$-catenin in order to determine activation of Wnt signaling pathway in 


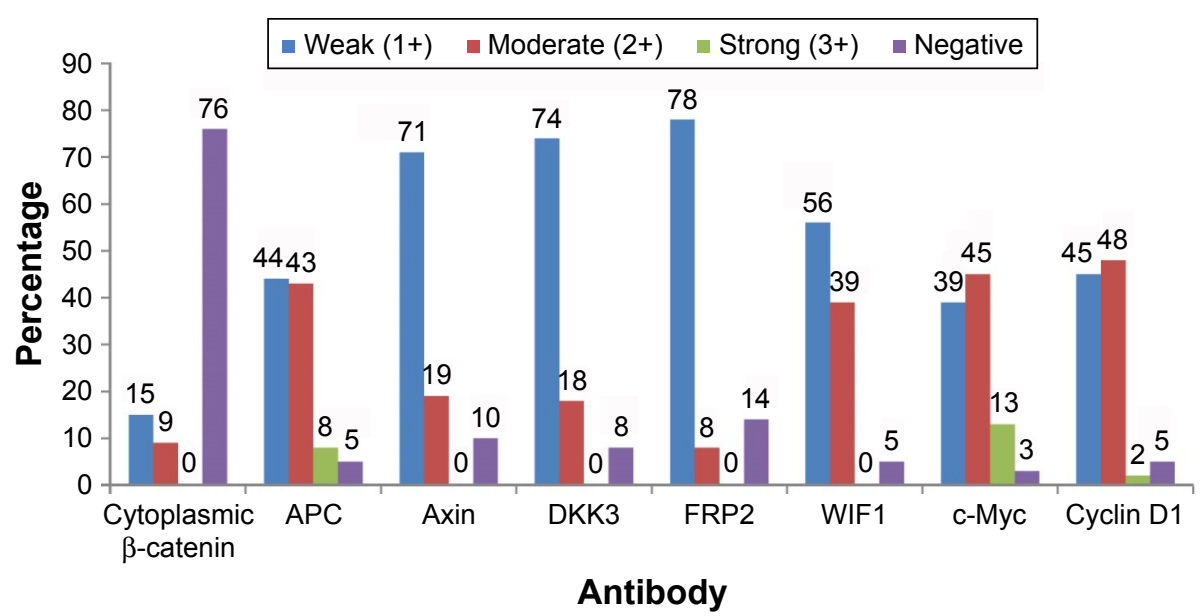

Figure I Histogram depicting proportion of breast carcinomas with different staining intensities of indicated Wnt signaling pathway molecules.

Abbreviations: APC, adenomatous polyposis coli; DKK3, Dickkopf Wnt signaling pathway inhibitor 3; FRP2, frizzled related protein 2; WIFI, Wnt inhibitory factor-I.

breast cancers. TMA was prepared using 69 FFPE breast cancer tissue blocks and immunohistochemical procedures were used as detailed in the section "Materials and methods". Eleven cores were lost/fragmented while performing the IHC, and thus $\beta$-catenin staining results were obtained for 58 cases. In $14 / 58$ (24\%) cases, cytoplasmic $\beta$-catenin reflecting pathway activation was observed (Figure 1). Nine (15\%) cases showed weak (1+) cytoplasmic $\beta$-catenin immunoreactivity, while $5(9 \%)$ cases were scored as moderately $(2+)$ positive (Figures 1 and 2). Six of the 58 cases were invasive lobular cancer while the remaining 52 were invasive ductal breast cancers. All the six lobular cancers were negative for $\beta$-catenin both at the membrane as well as in the cytoplasm (Figure 2). Thus, cytoplasmic $\beta$-catenin indicative of activation of Wnt signaling was detected in 14/52 (27\%) invasive ductal breast carcinomas in our patients. Additionally, all 52 ductal carcinomas were positive for membranous $\beta$-catenin. Majority (50 cases) were moderately (2+)/strongly (3+)
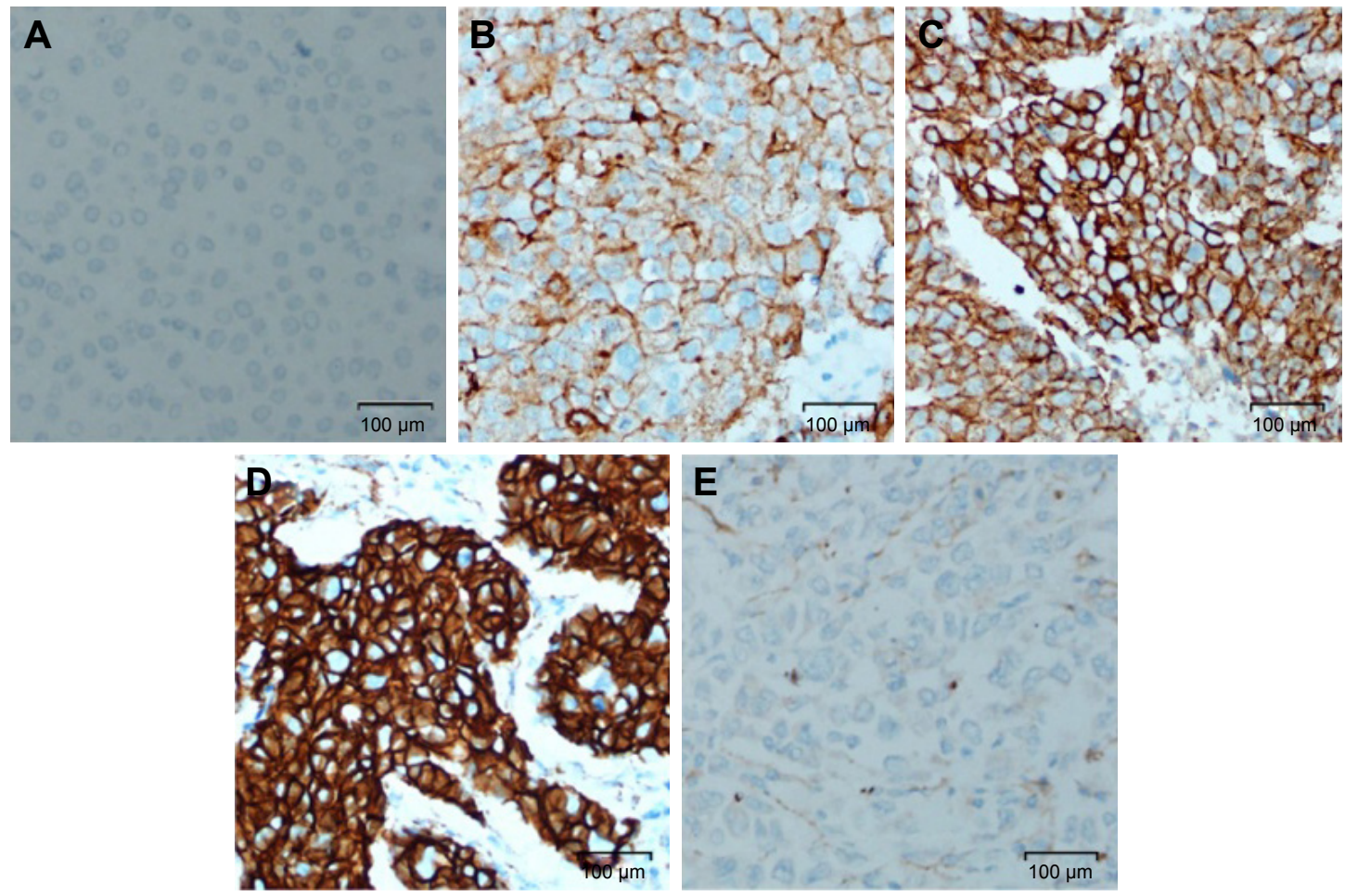

Figure 2 Cytoplasmic $\beta$-catenin immunoreactivity.

Notes: (A) Negative control (no primary antibody); (B) negative; (C) weak; (D) moderate; (E) invasive lobular breast carcinoma. Panels (A-D) are invasive ductal carcinomas. 
membrane positive, while only two cases were weakly (1+) positive at the membrane.

The tumor suppressors APC and Axin are components of the $\beta$-catenin destruction complex. Six tissue cores for APC and seven tissue cores for Axin on the TMA were lost/ fragmented during the staining procedure. Thus, APC and Axin staining were analyzed for 63 and 62 cases, respectively. APC expression was lost in 3/63 (5\%), while weak $(1+)$, moderate $(2+)$, and strong (3+) immunoreactivity was observed in 28/63 (44\%), 27/63 (43\%), and 5/63 (8\%) of breast cancers, respectively (Figure 3). Expression of Axin was lost in 6/62 (10\%) cases. Weak (1+) staining was observed in majority $(44 / 62 ; 71 \%)$ of the cases while moderate intensity (2+) was exhibited in 12/62 (19\%) breast cancers (Figure 3). Loss of APC and Axin was mutually exclusive and none of the breast cancer cases exhibited loss of both tumor suppressors. Thus, loss of expression of either APC or Axin together constituted 9/63 (14\%) cases.

\section{Analyses of negative regulators of $\mathrm{Wnt}$ pathway}

Wnt signaling pathway is regulated by several naturally expressing negative regulators such as members of the Dickkopf (DKKs) family, SFRPs, and WIF1. Downregulation of these regulators results in activation of the Wnt signaling pathway. We analyzed expression of DKK3, FRP2, and WIF1 in 69 breast cancer cases arising in Saudi Arabian patients. Immunohistochemical staining procedures resulted in loss/fragmentation of four, five, and seven cores from the tissue array for DKK3, FRP2, and WIF1, respectively. Loss of DKK3 was observed in 5/65 (8\%) of the cases, while FRP2 and WIF1 expression was not observed in 9/64 (14\%)
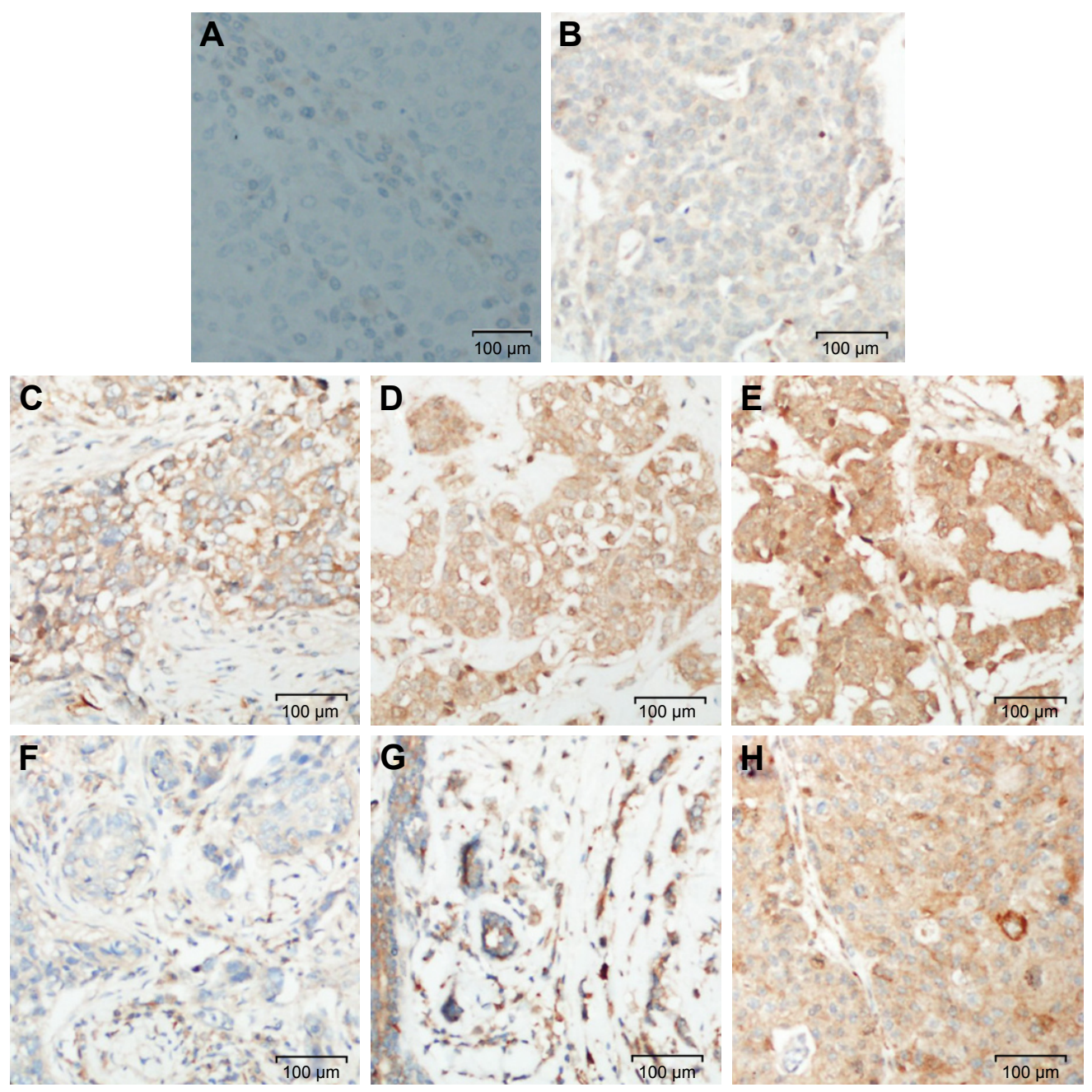

Figure $3 \mathrm{APC}$ and Axin immunohistochemical staining in breast carcinomas.

Notes: (A) Negative control (no primary antibody); (B) negative; (C) weak; (D) moderate; (E) strong; (F) negative; (G) weak; (H) moderate. Panels (B-E) are for APC and $(\mathbf{F}-\mathbf{H})$ are for Axin.

Abbreviation: APC, adenomatous polyposis coli. 
and 3/62 (5\%) cases, respectively (Figure 1). Representative immunohistochemical reactivity is shown for DKK3, FRP2, and WIF1 (Figure 4). Combining the data for these three negative regulators of Wnt signaling in a manner that each breast cancer is negative for DKK3 and/or FRP2 and/or WIF1 suggests that in $20 \%$ of the cases, expression of either one or more than one of these molecules are absent.

\section{Cumulative aberrations in Wnt signaling pathway}

Activity of the canonical Wnt pathway can be indicated by elevated levels of $\beta$-catenin in the nucleus and/or cytoplasm. Activation of this pathway can be achieved by aberration in one or more components of the pathway. Combining the data for cytoplasmic $\beta$-catenin along with deregulated expression
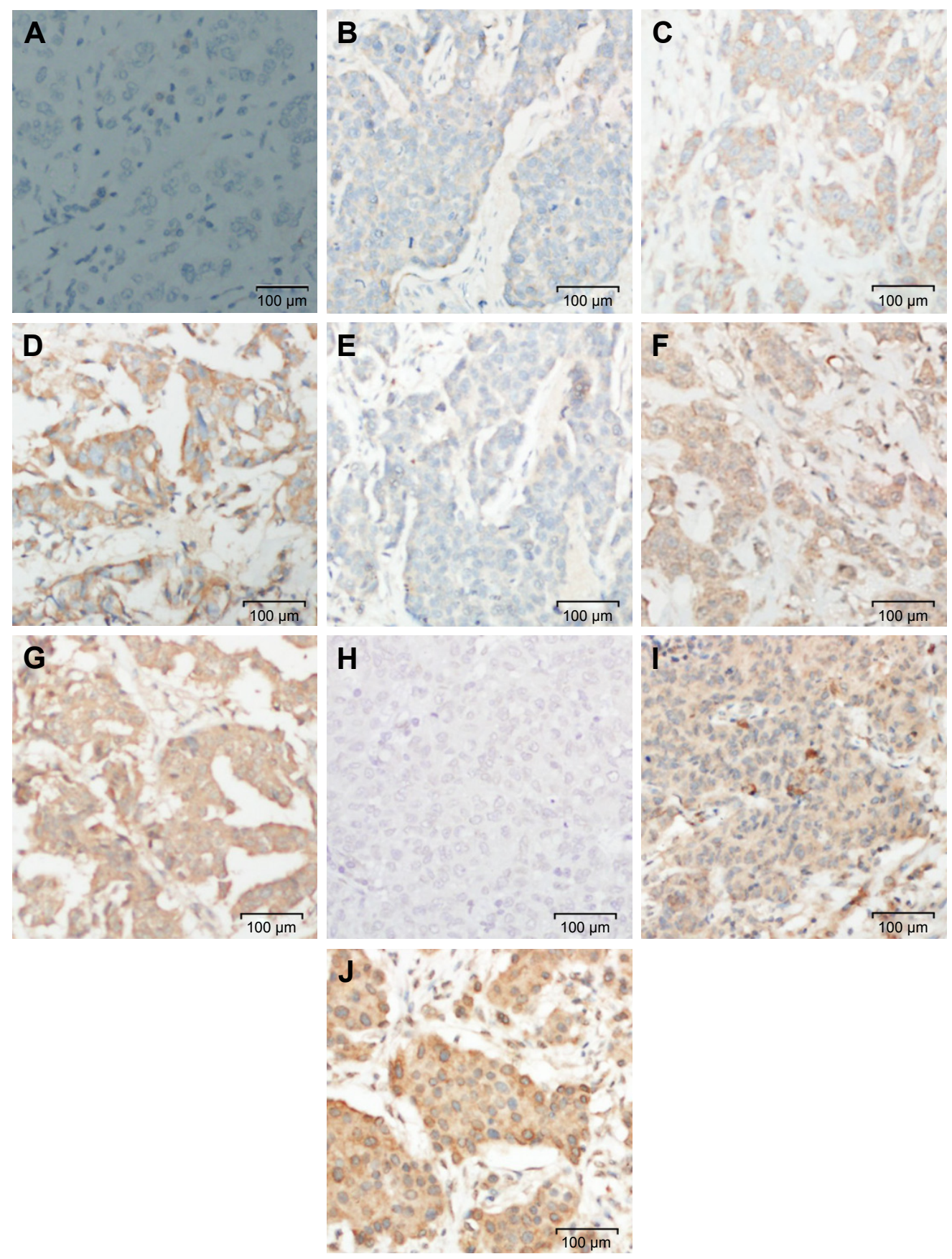

Figure 4 Immunostaining of negative regulators of Wnt pathway in breast carcinomas.

Notes: (A) Negative control (no primary antibody); Panels (B-D) represent DKK3, (B) negative, (C) weak, (D) moderate. Panels (E-G) represent FRP2, (E) negative, (F) weak, (G) moderate. Panels $(\mathbf{H}-\mathbf{J})$ represent WIFI, (H) negative, $(\mathbf{I})$ weak, and (J) moderate.

Abbreviations: DKK3, Dickkopf Wnt signaling pathway inhibitor 3; FRP2, frizzled-related protein 2; WIFI, Wnt inhibitory factor I; Wnt, wingless and integration site growth factor. 
in one or more of the analyzed molecules APC, Axin, DKK3, FRP2, and WIF1 suggests that aberrations in the Wnt pathway components could reach up to 47\% (29/62) of breast cancers in our cohort. In 33 cases, we did not observe deregulation of the examined molecules. Of the 14 cases that showed accumulation of cytoplasmic $\beta$-catenin, only two cases had aberrations in the examined wnt pathway components (one case was negative for Axin and FRP2 and the other negative for Axin and DKK3). While there was downregulation of tumor suppressors APC/Axin or the negative regulators DKK3/FRP2/WIF1, accumulation of cytoplasmic $\beta$-catenin was not seen in 15 breast cancers.

\section{Expression of Wnt signaling target c-Myc and Cyclin DI}

Immunostaining scores for c-Myc could be assessed for 62 cancer cases as seven tissue cores were lost/fragmented during the staining procedures. As depicted in Figure 1, majority (60/62\%-97\%) of the breast cancer cases exhibited varying degrees of c-Myc positivity [weak (1+) in 24/62 $(39 \%)$, moderate $(2+)$ in $28 / 62(45 \%)$, and strong $(3+)$ in $8 / 62(13 \%)]$. Collating cytoplasmic $\beta$-catenin that was seen in 14 cases, an indicator of Wnt pathway activation, with the c-Myc expression revealed that all but one case that was lost/fragmented during staining were positive for c-Myc expression. Representative micrographs for c-Myc immunoreactivity are shown in Figure 5.

Cyclin D1 staining scores could be assessed in 58 cancer cases. Eleven tissue cores were lost/fragmented during IHC staining procedures. Majority (55/58\%-95\%) of breast cancers stained positively for cyclin D1 expression to varying intensities [weak (1+) in 26/58 (45\%), moderate (2+) in $28 / 58(48 \%$ ), and strong (3+) in $1 / 58(2 \%)$ ] (Figure 1). Thus, $50 \%$ of the breast cancers exhibited moderate-to-strong
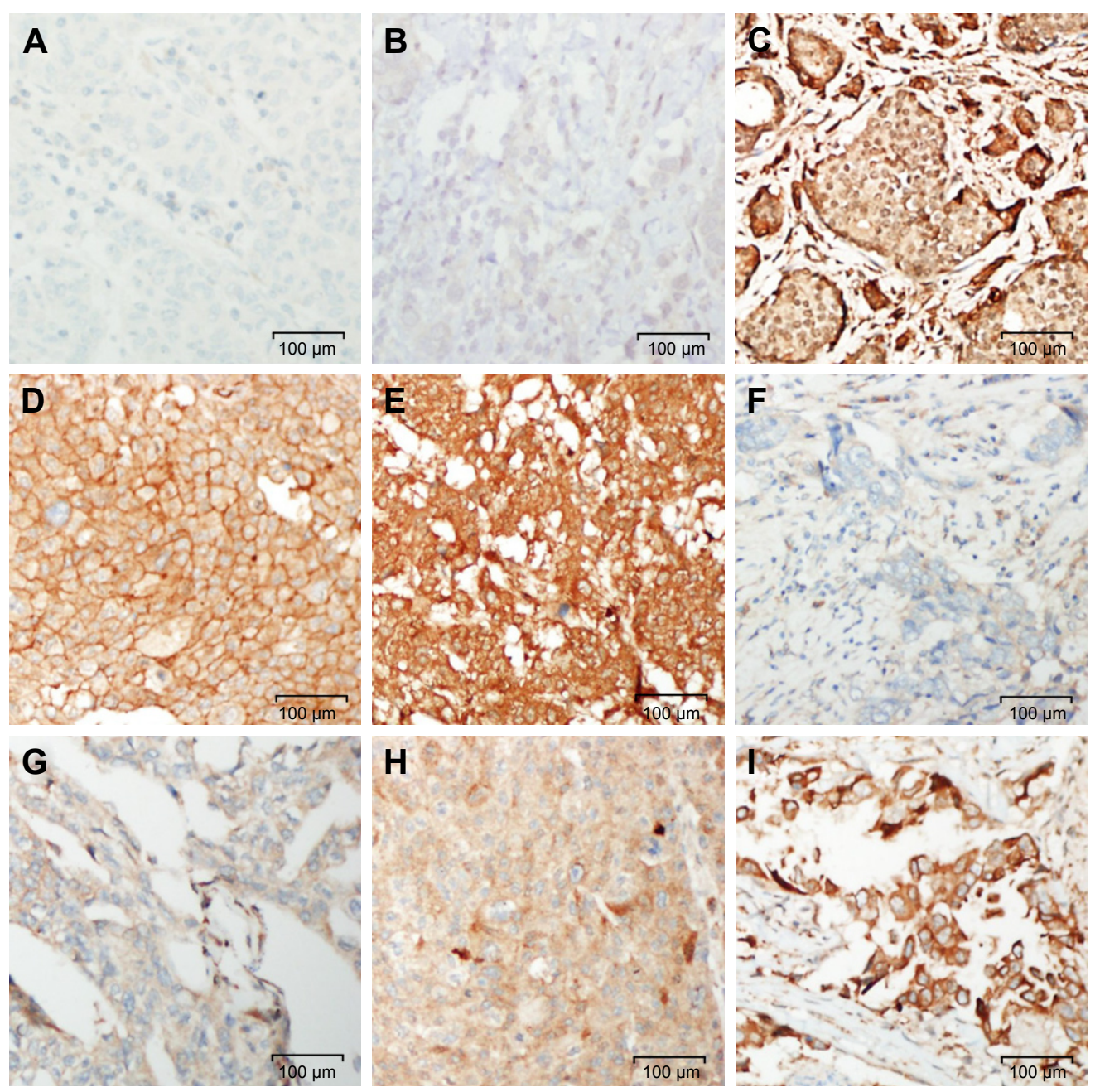

Figure 5 c-Myc and cyclin DI immunostaining in breast carcinomas.

Notes: (A) Negative control (no primary antibody); (B) negative; (C) weak; (D) moderate; (E) strong; (F) negative; (G) weak; (H) moderate; (I) strong. Panels (B-E) depict c-Myc staining and $(\mathbf{F}-\mathbf{I})$ depict cyclin DI staining. 
Table I Association of Wnt pathway with clinicopathological parameters

\begin{tabular}{|c|c|c|c|c|c|c|c|c|}
\hline & \multirow[t]{2}{*}{$\mathbf{n}$} & \multicolumn{2}{|c|}{ Cytoplasmic $\beta$-catenin } & \multirow[t]{2}{*}{$p$-value ${ }^{a}$} & \multirow[t]{2}{*}{$n$} & \multicolumn{2}{|c|}{$\begin{array}{l}\text { Wnt pathway aberration (Cyto } \beta \text {-catenin }{ }^{+} / \\
\text {APC-IAxin-/DKK3-/FRP2-/WIFI I }^{-} \text {) }\end{array}$} & \multirow[t]{2}{*}{$p$-value ${ }^{a}$} \\
\hline & & Positive & Negative & & & Yes & No & \\
\hline Age & 58 & & & 0.3630 & 62 & & & 1.0000 \\
\hline$\leq 50$ years & & 5 & 23 & & & 14 & 17 & \\
\hline$>50$ years & & 9 & 21 & & & 15 & 16 & \\
\hline Triple-negative & 58 & & & 0.6909 & 62 & & & 0.5216 \\
\hline Yes & & 3 & 7 & & & 7 & 5 & \\
\hline No & & II & 37 & & & 22 & 28 & \\
\hline Grade & 58 & & & 0.3192 & 62 & & & 0.6960 \\
\hline I & & 0 & 6 & & & 4 & 3 & \\
\hline $2+3$ & & 14 & 38 & & & 25 & 30 & \\
\hline
\end{tabular}

Notes: aFisher's exact test, two-tailed; $p \leq 0.05$ considered significant.

immunoreactivity for cyclin D1 in our cohort. Of the 14 cases that stained for cytoplasmic $\beta$-catenin, 12 cases were positive for cyclin D1 while one was negative and one lost/fragmented during staining procedure. Representative images for cyclin D1 staining are shown in Figure 5.

\section{Association of Wnt pathway activation with clinicopathological parameters}

The age of onset of breast cancer in Saudi Arabian women is significantly lower compared to patients in the USA. Hence, we sought to examine if there is an association between activation of the Wnt pathway and age of onset of breast cancer. Furthermore, we also correlated tumor grade as well as receptor status (triple-negative vs non-triplenegative breast cancer) with the activation of Wnt signaling. As shown in Table 1, cytoplasmic $\beta$-catenin, an indicator of Wnt pathway activation, alone or in combination with downregulated expression of APC/Axin/DKK3/FRP2/WIF1 was not associated with age of onset of the disease, tumor grade, and TNBCs.

\section{Discussion}

$\beta$-catenin is a protein that exhibits totally unrelated diverse functions. It is associated with E-cadherin in the formation of cell-cell adhesion structures named adherens junctions and also functions as a transcriptional coactivator in the canonical Wnt signaling pathway by partnering with TCF/LEF to transcribe Wnt target genes. Thus, detection of nuclear and/or cytoplasmic $\beta$-catenin is suggestive of the activation of Wnt signaling cascade. In this study, cytoplasmic $\beta$-catenin was detected in $27 \%$ of the invasive ductal breast carcinomas, while none of the invasive lobular breast cancer cases exhibited detectable cytoplasmic or membranous $\beta$-catenin. Absence of E-cadherin and $\beta$-catenin has been reported in invasive lobular breast carcinomas in earlier studies and are being used as immunohistochemical markers to distinguish between lobular and ductal cancers. ${ }^{31,32}$ Interestingly, cytoplasmic accumulation of $\beta$-catenin and activation of Wnt signaling pathway have been associated with poor prognosis in invasive breast carcinomas. ${ }^{33,34}$ The frequency of cytoplasmic localization of $\beta$-catenin in our cohort of invasive ductal breast cancer cases is within the range (8\%-96\%) detected in other studies. ${ }^{26,34-39}$ In colorectal cancers, the stabilized $\beta$-catenin is mostly seen in the nucleus, while few studies have reported nuclear $\beta$-catenin in breast carcinomas. ${ }^{26,39,40}$ Similar to our findings, numerous studies have detected stabilized $\beta$-catenin in the cytoplasm and not in the nucleus of breast cancer cells..$^{34,35,41}$ The molecular mechanisms responsible for mislocalization of $\beta$-catenin are unclear at the moment and may be attributed to aberrations in its binding partners GSK $3 \beta$, APC, or Axin. There could be several reasons for the lack of detection of nuclear $\beta$-catenin in breast cancers such as low levels in the nucleus beyond the detectable sensitivity of IHC or a quick and effective shuttling of $\beta$-catenin from the nucleus by normal APC as suggested in a study by Henderson. ${ }^{42}$

Axin and APC are key components of the $\beta$-catenin destruction complex that controls level of $\beta$-catenin in the cytoplasm. In breast cancer samples, reduced or absence of expression of APC protein has been reported in 34\%-64\% of the cases. ${ }^{38,43,44}$ Numerous studies have attributed loss of expression of APC protein to promoter methylation linking it to the predisposition to breast cancer. A recent meta-analysis of 35 studies by Zhou et al demonstrated $A P C$ promoter methylation to be significantly associated with breast cancer pathogenesis (odds ratio $=8.92,95 \%$ CI: $5.12-15.52$ ).${ }^{45}$ Furthermore, significant upregulation of microRNA-1229, which directly targets $A P C$, has been demonstrated as a 
novel mechanism of activating $\mathrm{Wnt} / \beta$-catenin signaling in breast cancer. ${ }^{46}$ We observed weak/absence of expression of APC in $49 \%$ of breast cancer tissues, which is in line with frequencies observed by other investigators. Axin is a scaffold protein that by interacting with other members of the destruction complex coordinates phosphorylation and degradation of $\beta$-catenin and thus negatively regulates Wnt signaling. Deregulation of axin has been found in many human malignancies including colorectal cancer, medulloblastoma, hepatocellular carcinoma, and esophageal and other cancers. ${ }^{47,48}$ Current knowledge regarding axin in breast cancer is limited as not many studies have reported axin alterations in breast carcinomas. While no mutation was found in the axin 1 gene in breast cancers by Ozaki et al, loss of expression of axin was detected in $52 \%$ of breast cancer cases by He et al. ${ }^{38,49}$ We observed weak expression of axin in $71 \%$ breast cancer samples and complete loss of expression in $10 \%$ cases. As mutations in the axin gene are rare, reduced or loss of axin expression could be due to promoter hypermethylation as seen by Yang et al in lung cancer. ${ }^{50}$ Alternatively, tankyrases, which are members of the poly ADP-ribose polymerase family of poly-ADP-ribosylation enzymes that controls axin levels, may have higher activity in cancer cells as inhibition of tankyrase in breast cancer cells increases axin levels while inhibiting cell migration and suppresses cell growth in serum-deprived condition. ${ }^{51}$

Upregulation of $\beta$-catenin was demonstrated in human tumor cells including breast cancers by a novel mechanism involving Wnt autocrine signaling in the absence of obvious lesions in either APC or $\beta$-catenin. ${ }^{52}$ Extracellular Wnt antagonists, DKK and FRP, caused a dramatic downregulation of $\beta$-catenin levels associated with alteration of biological properties and increased expression of differentiation markers. ${ }^{52}$ Activation of Wnt signaling pathway in breast carcinomas has been attributed to the reduced expression of the soluble extracellular Wnt inhibitors. ${ }^{53-55}$ Four DKK gene members have been identified so far. DKK1, DKK2, and DKK4 antagonize canonical Wnt/ $\beta$-catenin signaling by interaction with LDL-receptor-related proteins (LRP5 and LRP6) and cause its endocytosis through formation of a ternary complex with the transmembrane protein Kremen. ${ }^{56-59}$ In contrast, DKK3 does not sequester LRPs or Wnt ligands. ${ }^{60-62}$ Its function in antagonizing nuclear $\beta$-catenin levels, the hallmark of an activated Wnt pathway often found in human tumor tissues, has received conflicting reports. ${ }^{63-65}$ Aberrant downregulated expression of DKK3 by promoter hypermethylation has frequently been demonstrated in human breast cancers. ${ }^{54,66-68}$ Confirming these observations, our breast cancer tissues exhibited complete loss of expression of DKK3 in $8 \%$ and weak expression in $74 \%$ of the cases. Ectopic expression of DKK3 in breast cancer cells showed antiproliferative activity, induced apoptosis by activating JNK signaling, and suppressed cell migration. ${ }^{68}$ It also inhibited canonical Wnt signaling by blocking activation of $\beta$-catenin and its downstream genes $c-M y c$ and $c y c l i n D 1$ by abrogating its nuclear translocalization. ${ }^{68}$ Recently, Lorsy et al reported loss of expression of DKK3 in breast cancers and found most abundant reduced expression in the highly aggressive TNBC subtype. They also noted that reduced $D K K 3$ mRNA expression was significantly associated with unfavorable patient prognosis. ${ }^{69}$

SFRPs share sequence similarity with the Frizzled receptor CRD (cysteine-rich domain) but lack the transmembrane and intracellular domains. ${ }^{70-72}$ Through its CRD, FRP exhibits the ability to bind Wnt, form dimers, and heterodimerize with frizzled. ${ }^{71,73-75}$ Thus, FRP may act not only to sequester Wnts but also to inhibit Wnt signaling via formation of nonfunctional complexes with the frizzled receptor. Frequent epigenetic silencing of SFRP 2 gene ranging from $54 \%$ to $83 \%$ has been demonstrated in primary human breast carcinomas. ${ }^{43,76-78}$ In our breast cancer cohort, negative staining for SFRP2 protein was seen in $14 \%$, while weak expression was observed in $78 \%$ of the cases. Strong reduction of SFRP 2 protein expression was also observed in $74 \%$ of breast carcinomas by Veeck et al in German patients. ${ }^{77}$ Detection of $S F R P 2$ promoter methylation has been proposed as a biomarker for early detection and prediction of relapse-free survival in breast cancer patients. ${ }^{78,79}$ Contrary to its tumor-suppressive effect by antagonizing canonical Wnt signaling, SFRP2 has been found to induce tumor growth by promoting angiogenesis through noncanonical Wnt calcineurin/NFATc3 pathway. ${ }^{80}$ Overexpression of SFRP2 was detected in the vasculature of different types of solid tumors including breast, and various in vitro as well as in vivo experiments demonstrated its role as a stimulator of angiogenesis. ${ }^{80,81}$ Consistent with these findings, antagonizing SFRP2 with monoclonal antibody was shown to inhibit growth of angiosarcoma and triple-negative breast carcinoma in vivo. ${ }^{82}$ Further studies would be required to clarify the role of SFRP2 in tumorigenesis and whether it influences different pathways in different cell types to bring about contradicting outcome.

WIF1 is another secreted antagonist that can bind Wnt proteins and inhibits their interaction with the frizzled receptor leading to termination of transcription of genes activated by the $\beta$-catenin/TCF/LEF transcriptional complex. ${ }^{83}$ Decreased WIF1 mRNA and protein expression has been 
observed in several cancers. ${ }^{55}$ Epigenetic silencing of WIF1 gene by promoter methylation has been reported in $63 \%-82 \%$ of sporadic and hereditary human breast carcinomas. . $^{24,67,84,85}$ Strong reduction of WIF1 protein expression was demonstrated in $60 \%$ of breast cancers, and this loss of expression was suggested to be an early event in tumorigenesis. ${ }^{55} \mathrm{We}$ observed loss of WIF1 protein expression in 5\% and weak expression in $56 \%$ of breast cancers, which is similar to frequencies of WIF1 aberrations in other populations. Cai et al reported overexpression of microRNA-374a that directly targeted and suppressed WIF 1 , consequently activating Wnt signaling in breast cancer cell lines as well as in primary breast tumors from patients with distance metastasis and was associated with poor metastasis-free survival. ${ }^{86}$

In this study, accumulation of cytoplasmic $\beta$-catenin was observed in 14 breast cancers, and of these only two cases can be attributed to loss of expression of Axin, FRP2, or DKK3, thus suggesting the possibility of deregulation of other members of the Wnt signaling pathway. Additionally, cytoplasmic $\beta$-catenin was not detected in 15 breast cancers in which downregulation of tumor suppressors APC and Axin or the negative regulators DKK3, FRP2, and WIF1 was observed. It is possible that in these 15 cases, $\beta$-catenin can still be efficiently phosphorylated and degraded because of a compensatory effect exhorted by other family members or by some as yet unknown mechanisms.

A number of genes have been identified as targets of canonical Wnt signaling, although there is variability among Wnt target genes in different cell systems. ${ }^{87}$ Target genes included $c$-myc and cyclin D1, known oncogenes that contribute to malignant progression, cyclooxygenase-2, Axin-2, LEF-1, peroxisome proliferator-activated receptor $\delta$, fibronectin, the dominant negative helix-loop-helix transcriptional regulator $I d 2$, metalloproteinase matrilysin (MMP-7), and WISP-1 (Wnt-1-induced secreted protein). ${ }^{15}$ Moreover, mutant $\beta$-catenin has been found to induce p53 upregulation through activation of p19/ARF. ${ }^{87}$ Thus, a number of genes in pathways implicated in malignant progression appear to be activated by Wnt, although the identification of critical effectors of constitutive Wnt activation in human cancer cells still need further investigations. Additionally, Nakamura et al recently demonstrated that recruitment of $\beta$-catenin to Wnt-response elements does not imply expression of Wnt target genes but the transcriptional responses to Wnt signaling are context dependent such as embryonic stages, tissues, and cell lineages. ${ }^{88}$

A strong correlation between abnormal expression of $\beta$-catenin and overexpression of cyclin D1 in breast cancers was observed by several investigators. ${ }^{26,38,49,89}$ Lin et al found that cyclin D1 expression and activated $\beta$-catenin were associated with poorer prognosis. ${ }^{26}$ While significantly strong correlation of abnormal expression of $\beta$-catenin and c-Myc overexpression was observed by Ozaki et al, similar association was not demonstrated by $\mathrm{He}$ et al in human breast carcinomas. ${ }^{38,49}$ In our breast cancer cohort, positive correlation between cytoplasmic $\beta$-catenin and cyclin D1 as well as with c-Myc overexpression was not observed ( $\mathrm{r}=-0.3347, p=0.01337$ for cyclin D1 and $\mathrm{r}=-0.10049$, $p=0.46,116$ for c-Myc). Statistically significant negative correlation between cytoplasmic $\beta$-catenin and overexpression of cyclin D1 was observed that can be attributed to the higher expression of cyclin D1 by other mechanisms independent of $\beta$-catenin signaling.

We observed that activation of Wnt signaling was not associated with age of onset of breast cancers, tumor grade, and more aggressive TNBCs, suggesting that activation of Wnt pathway in general may be involved in the pathogenesis of breast carcinomas but does not influence the studied parameters. However, an association of Wnt signaling activation in breast cancers with other clinicopathological parameters such as tumor stage and prognosis cannot be ruled out. Contradictory findings pertaining to association of Wnt signaling pathway activation and clinicopathological characteristics of breast tumors in earlier studies have been reported. Similar to our findings, no associations were observed between nucleocytoplasmic $\beta$-catenin expression and clinicopathological features such as age, tumor grade, and hormone receptors as well as HER2 by Karayiannakis et al and Khalil et al. ${ }^{35,36}$ Lopez-Knowles et al, while finding no association similar to our observation between cytoplasmic $\beta$-catenin and age of the patient, have reported statistically significant association with the tumor grade, tumor size, ER, and PR. ${ }^{34}$ Similarly, Geyer et al have reported association of activation of Wnt signaling pathway with tumor grade and TNBCs. ${ }^{33}$

\section{Conclusion}

This is the first study demonstrating the activation of Wnt signaling pathway in Saudi Arabian breast cancer patients. Cytoplasmic $\beta$-catenin, a surrogate marker for Wnt pathway activation, was observed in $27 \%$ of invasive ductal breast carcinomas. Combining the data for cytoplasmic $\beta$-catenin along with aberrations in one or more of the analyzed molecules (cytoplasmic $\beta$-catenin ${ }^{+} / \mathrm{APC}^{-} / \mathrm{Axin}^{-} / \mathrm{DKK}^{-} / \mathrm{FRP}^{-} / \mathrm{WIF}^{-}{ }^{-}$) suggests aberrations of Wnt pathway components in nearly half (29/62) of the breast cancers in our cohort. A larger study 
with more number of breast cancers and including additional family members of the negative regulators of Wnt pathway would be highly recommended. Additionally, it would be interesting to investigate the mutational status of $A P C$, Axin, and $\beta$-catenin as well as DNA promoter methylation of the negative regulators of the pathway. Correlating treatment outcome and patient survival data with Wnt pathway activation will also provide valuable information. Nonetheless, this pilot study provides compelling evidence of high level of deregulated expression of the Wnt signaling pathway proteins, suggesting its role in the pathogenesis of breast cancers arising in Saudi patients who may benefit from the development of therapeutic drugs targeting this pathway.

\section{Acknowledgments}

We thank Mr Osman and Mr Gulzar from the department of pathology, King Khalid University Hospital (KKUH), King Saud University, Riyadh for their technical help. The authors are grateful to the Deanship of Scientific Research, King Saud University for funding through Vice Deanship of Scientific Research Chairs.

\section{Disclosure}

The authors report no conflicts of interest in this work.

\section{References}

1. Ferlay J, Soerjomataram I, Ervik M, et al. GLOBOCAN 2012 v1.0, Cancer Incidence and Mortality Worldwide: IARC CancerBase No. 11 [Internet]. Lyon, France. In: International Agency for Research on Cancer; 2013. Available from: http://globocan.iarc.fr. Accessed April 4, 2015.

2. Allred DC, Mohsin SK, Fuqua SA. Histological and biological evolution of human premalignant breast disease. Endocr Relat Cancer. 2001; $8(1): 47-61$.

3. Bombonati A, Sgroi DC. The molecular pathology of breast cancer progression. J Pathol. 2011;223(2):307-317.

4. Saudi Cancer Registry. Cancer Incidence Report Saudi Arabia 2010; 2014.

5. Elkum N, Dermime S, Ajarim D, et al. Being 40 or younger is an independent risk factor for relapse in operable breast cancer patients: the Saudi Arabia experience. BMC Cancer. 2007;7:222.

6. Anders CK, Hsu DS, Broadwater G, et al. Young age at diagnosis correlates with worse prognosis and defines a subset of breast cancers with shared patterns of gene expression. J Clin Oncol. 2008;26(20): 3324-3330.

7. Gabriel CA, Domchek SM. Breast cancer in young women. Breast Cancer Res. 2010;12(5):212.

8. Logan CY, Nusse R. The Wnt signaling pathway in development and disease. Annu Rev Cell Dev Biol. 2004;20:781-810.

9. Haegebarth A, Clevers H. Wnt signaling, lgr5, and stem cells in the intestine and skin. Am J Pathol. 2009;174(3):715-721.

10. Huelsken J, Vogel R, Erdmann B, Cotsarelis G, Birchmeier W. BetaCatenin controls hair follicle morphogenesis and stem cell differentiation in the skin. Cell. 2001;105(4):533-545.

11. Kuhnert F, Davis CR, Wang HT, et al. Essential requirement for Wnt signaling in proliferation of adult small intestine and colon revealed by adenoviral expression of Dickkopf-1. Proc Natl Acad Sci U S A. 2004; 101(1):266-271.
12. Brennan KR, Brown AM. Wnt proteins in mammary development and cancer. J Mammary Gland Biol Neoplasia. 2004;9(2):119-131.

13. Kimelman D, Xu W. Beta-catenin destruction complex: insights and questions from a structural perspective. Oncogene. 2006;25(57): 7482-7491.

14. MacDonald BT, Tamai K, He X. Wnt/beta-catenin signaling: components, mechanisms, and diseases. Dev Cell. 2009;17(1):9-26.

15. Giles RH, van Es JH, Clevers H. Caught up in a Wnt storm: Wnt signaling in cancer. Biochim Biophys Acta. 2003;1653(1):1-24.

16. Nusse R, Varmus HE. Many tumors induced by the mouse mammary tumor virus contain a provirus integrated in the same region of the host genome. Cell. 1982;31(1):99-109.

17. Nusse R, Varmus HE. Wnt genes. Cell. 1992;69(7):1073-1087.

18. Polakis P. Wnt signaling and cancer. Genes Dev. 2000;14(15):1837-1851.

19. Clevers H. Wnt/beta-catenin signaling in development and disease. Cell. 2006;127(3):469-480.

20. Furuuchi K, Tada M, Yamada H, et al. Somatic mutations of the APC gene in primary breast cancers. Am J Pathol. 2000;156(6):1997-2005.

21. Jin Z, Tamura G, Tsuchiya T, et al. Adenomatous polyposis coli (APC) gene promoter hypermethylation in primary breast cancers. Br J Cancer. 2001;85(1):69-73.

22. Sarrio D, Moreno-Bueno G, Hardisson D, et al. Epigenetic and genetic alterations of APC and CDH1 genes in lobular breast cancer: relationships with abnormal E-cadherin and catenin expression and microsatellite instability. Int J Cancer. 2003;106(2):208-215.

23. Polakis P. The oncogenic activation of beta-catenin. Curr Opin Genet Dev. 1999;9(1):15-21.

24. Ai L, Tao Q, Zhong S, et al. Inactivation of Wnt inhibitory factor-1 (WIF1) expression by epigenetic silencing is a common event in breast cancer. Carcinogenesis. 2006;27(7):1341-1348.

25. Ayyanan A, Civenni G, Ciarloni L, et al. Increased Wnt signaling triggers oncogenic conversion of human breast epithelial cells by a Notch-dependent mechanism. Proc Natl Acad Sci US A. 2006;103(10): 3799-3804.

26. Lin SY, Xia W, Wang JC, et al. Beta-catenin, a novel prognostic marker for breast cancer: its roles in cyclin D1 expression and cancer progression. Proc Natl Acad Sci U S A. 2000;97(8):4262-4266.

27. Veeck J, Niederacher D, An H, et al. Aberrant methylation of the Wnt antagonist SFRP1 in breast cancer is associated with unfavorable prognosis. Oncogene. 2006;25(24):3479-3488.

28. Ryo A, Nakamura M, Wulf G, Liou YC, Lu KP. Pin1 regulates turnover and subcellular localization of beta-catenin by inhibiting its interaction with APC. Nat Cell Biol. 2001;3(9):793-801.

29. Nakopoulou L, Mylona E, Papadaki I, et al. Study of phospho-betacatenin subcellular distribution in invasive breast carcinomas in relation to their phenotype and the clinical outcome. Mod Pathol. 2006; 19(4):556-563.

30. Detre S, Saclani Jotti G, Dowsett M. A “quickscore" method for immunohistochemical semiquantitation: validation for estrogen receptor in breast carcinomas. J Clin Pathol. 1995;48(9):876-878.

31. Turashvili G, Bouchal J, Burkadze G, Kolar Z. Differentiation of tumors of ductal and lobular origin: I. Proteomics of invasive ductal and lobular breast carcinomas. Biomed Pap Med Fac Univ Palacky Olomouc Czech Repub. 2005;149(1):57-62.

32. Morrogh M, Andrade VP, Giri D, et al. Cadherin-catenin complex dissociation in lobular neoplasia of the breast. Breast Cancer Res Treat. 2012;132(2):641-652.

33. Geyer FC, Lacroix-Triki M, Savage K, et al. beta-Catenin pathway activation in breast cancer is associated with triple-negative phenotype but not with CTNNB1 mutation. Mod Pathol. 2011;24(2): 209-231.

34. Lopez-Knowles E, Zardawi SJ, McNeil CM, et al. Cytoplasmic localization of beta-catenin is a marker of poor outcome in breast cancer patients. Cancer Epidemiol Biomarkers Prev. 2010;19(1):301-309.

35. Karayiannakis AJ, Nakopoulou L, Gakiopoulou H, Keramopoulos A, Davaris PS, Pignatelli M. Expression patterns of beta-catenin in in situ and invasive breast cancer. Eur J Surg Oncol. 2001;27(1):31-36. 
36. Khalil S, Tan GA, Giri DD, Zhou XK, Howe LR. Activation status of Wnt/ss-catenin signaling in normal and neoplastic breast tissues: relationship to HER2/neu expression in human and mouse. PLoS One. 2012;7(3): 333421

37. Li S, Li S, Sun Y, Li L. The expression of $\beta$-catenin in different subtypes of breast cancer and its clinical significance. Tumor Biol. 2014;35(8):7693-7698.

38. Ozaki S, Ikeda S, Ishizaki Y, et al. Alterations and correlations of the components in the Wnt signaling pathway and its target genes in breast cancer. Oncol Rep. 2005;14(6):1437-1443.

39. Prasad CP, Gupta SD, Rath G, Ralhan R. Wnt signaling pathway in invasive ductal carcinoma of the breast: relationship between betacatenin, disheveled and cyclin D1 expression. Oncology. 2007;73(1-2): $112-117$.

40. Wong SC, Lo ES, Lee KC, Chan JK, Hsiao WL. Prognostic and diagnostic significance of beta-catenin nuclear immunostaining in colorectal cancer. Clin Cancer Res. 2004;10(4):1401-1408.

41. Abd El-Rehim D, Ali MM. Aberrant expression of beta-catenin in invasive ductal breast carcinomas. J Egypt Natl Canc Inst. 2009;21(2): $185-195$.

42. Henderson BR. Nuclear-cytoplasmic shuttling of APC regulates beta-catenin subcellular localization and turnover. Nat Cell Biol. 2000;2(9):653-660.

43. Mukherjee N, Bhattacharya N, Alam N, Roy A, Roychoudhury S, Panda CK. Subtype-specific alterations of the Wnt signaling pathway in breast cancer: clinical and prognostic significance. Cancer Sci. 2012; 103(2):210-220

44. Prasad CP, Mirza S, Sharma G, et al. Epigenetic alterations of CDH1 and APC genes: relationship with activation of Wnt/beta-catenin pathway in invasive ductal carcinoma of breast. Life Sci. 2008;83(9-10): 318-325.

45. Zhou D, Tang W, Wang W, Pan X, An HX, Zhang Y. Association between aberrant APC promoter methylation and breast cancer pathogenesis: a meta-analysis of 35 observational studies. PeerJ. 2016; 4:e2203.

46. Tan Z, Zheng H, Liu X, et al. MicroRNA-1229 overexpression promotes cell proliferation and tumorigenicity and activates Wnt/beta-catenin signaling in breast cancer. Oncotarget. 2016;7(17):24076-24087.

47. Mazzoni SM, Fearon ER. AXIN1 and AXIN2 variants in gastrointestinal cancers. Cancer Lett. 2014;355(1):1-8.

48. Salahshor S, Woodgett JR. The links between axin and carcinogenesis. J Clin Pathol. 2005;58(3):225-236.

49. He Y, Liu Z, Qiao C, Xu M, Yu J, Li G. Expression and significance of Wnt signaling components and their target genes in breast carcinoma. Mol Med Rep. 2014;9(1):137-143.

50. Yang LH, Xu HT, Li QC, et al. Abnormal hypermethylation and clinicopathological significance of Axin gene in lung cancer. Tumor Biol. 2013;34(2):749-757.

51. Bao R, Christova T, Song S, Angers S, Yan X, Attisano L. Inhibition of tankyrases induces Axin stabilization and blocks Wnt signaling in breast cancer cells. PLoS One. 2012;7(11):e48670.

52. Bafico A, Liu G, Goldin L, Harris V, Aaronson SA. An autocrine mechanism for constitutive Wnt pathway activation in human cancer cells. Cancer Cell. 2004;6(5):497-506.

53. Ugolini F, Charafe-Jauffret E, Bardou VJ, et al. WNT pathway and mammary carcinogenesis: loss of expression of candidate tumor suppressor gene SFRP1 in most invasive carcinomas except of the medullary type. Oncogene. 2001;20(41):5810-5817.

54. Veeck J, Bektas N, Hartmann A, et al. Wnt signaling in human breast cancer: expression of the putative Wnt inhibitor Dickkopf-3 (DKK3) is frequently suppressed by promoter hypermethylation in mammary tumors. Breast Cancer Res. 2008;10(5):R82.

55. Wissmann C, Wild PJ, Kaiser S, et al. WIF1, a component of the Wnt pathway, is down-regulated in prostate, breast, lung, and bladder cancer. J Pathol. 2003;201(2):204-212.

56. Bafico A, Liu G, Yaniv A, Gazit A, Aaronson SA. Novel mechanism of Wnt signaling inhibition mediated by Dickkopf-1 interaction with LRP6/Arrow. Nat Cell Biol. 2001;3(7):683-686.
57. He X, Semenov M, Tamai K, Zeng X. LDL receptor-related proteins 5 and 6 in Wnt/beta-catenin signaling: arrows point the way. Development. 2004;131(8):1663-1677.

58. Mao B, Wu W, Davidson G, et al. Kremen proteins are Dickkopf receptors that regulate Wnt/beta-catenin signaling. Nature. 2002; 417(6889):664-667.

59. Semenov MV, Tamai K, Brott BK, Kuhl M, Sokol S, He X. Head inducer Dickkopf-1 is a ligand for Wnt coreceptor LRP6. Curr Biol. 2001;11(12):951-961.

60. Krupnik VE, Sharp JD, Jiang C, et al. Functional and structural diversity of the human Dickkopf gene family. Gene. 1999;238(2):301-313.

61. Mao B, Niehrs C. Kremen2 modulates Dickkopf2 activity during Wnt/LRP6 signaling. Gene. 2003;302(1-2):179-183.

62. Mao B, Wu W, Li Y, et al. LDL-receptor-related protein 6 is a receptor for Dickkopf proteins. Nature. 2001;411(6835):321-325.

63. Hoang BH, Kubo T, Healey JH, et al. Dickkopf 3 inhibits invasion and motility of Saos-2 osteosarcoma cells by modulating the Wnt-betacatenin pathway. Cancer Res. 2004;64(8):2734-2739.

64. Kawano Y, Kitaoka M, Hamada Y, Walker MM, Waxman J, Kypta RM. Regulation of prostate cell growth and morphogenesis by Dickkopf-3. Oncogene. 2006;25(49):6528-6537.

65. Yue W, Sun Q, Dacic S, et al. Downregulation of Dkk3 activates betacatenin/TCF-4 signaling in lung cancer. Carcinogenesis. 2008;29(1): 84-92.

66. Kloten V, Becker B, Winner K, et al. Promoter hypermethylation of the tumor-suppressor genes ITIH5, DKK3, and RASSF1A as novel biomarkers for blood-based breast cancer screening. Breast Cancer Res. 2013;15(1):R4.

67. Veeck J, Wild PJ, Fuchs T, et al. Prognostic relevance of Wnt-inhibitory factor-1 (WIF1) and Dickkopf-3 (DKK3) promoter methylation in human breast cancer. BMC Cancer. 2009;9:217.

68. Xiang T, Li L, Yin X, et al. Epigenetic silencing of the WNT antagonist Dickkopf 3 disrupts normal Wnt/beta-catenin signaling and apoptosis regulation in breast cancer cells. J Cell Mol Med. 2013;17(10):1236-1246.

69. Lorsy E, Topuz AS, Geisler C, et al. Loss of dickkopf 3 promotes the tumorigenesis of basal breast cancer. PLoS One. 2016;11(7):e0160077.

70. Finch PW, He X, Kelley MJ, et al. Purification and molecular cloning of a secreted, Frizzled-related antagonist of Wnt action. Proc Natl Acad Sci U S A. 1997;94(13):6770-6775.

71. Leyns L, Bouwmeester T, Kim SH, Piccolo S, De Robertis EM. Frzb-1 is a secreted antagonist of Wnt signaling expressed in the Spemann organizer. Cell. 1997;88(6):747-756.

72. Wang S, Krinks M, Lin K, Luyten FP, Moos M Jr. Frzb, a secreted protein expressed in the Spemann organizer, binds and inhibits Wnt-8. Cell. 1997;88(6):757-766.

73. Bafico A, Gazit A, Pramila T, Finch PW, Yaniv A, Aaronson SA. Interaction of frizzled related protein (FRP) with Wnt ligands and the frizzled receptor suggests alternative mechanisms for FRP inhibition of Wnt signaling. J Biol Chem. 1999;274(23):16180-16187.

74. Lin K, Wang S, Julius MA, Kitajewski J, Moos M Jr., Luyten FP. The cysteine-rich frizzled domain of Frzb-1 is required and sufficient for modulation of Wnt signaling. Proc Natl Acad Sci U S A. 1997;94(21): 11196-11200.

75. Rattner A, Hsieh JC, Smallwood PM, et al. A family of secreted proteins contains homology to the cysteine-rich ligand-binding domain of frizzled receptors. Proc Natl Acad Sci U S A. 1997;94(7):2859-2863.

76. Suzuki H, Toyota M, Carraway H, et al. Frequent epigenetic inactivation of Wnt antagonist genes in breast cancer. Br J Cancer. 2008; 98(6):1147-1156.

77. Veeck J, Noetzel E, Bektas N, et al. Promoter hypermethylation of the SFRP2 gene is a high-frequent alteration and tumor-specific epigenetic marker in human breast cancer. Mol Cancer. 2008;7:83.

78. Hill VK, Ricketts C, Bieche I, et al. Genome-wide DNA methylation profiling of $\mathrm{CpG}$ islands in breast cancer identifies novel genes associated with tumorigenicity. Cancer Res. 2011;71(8):2988-2999.

79. Li Z, Guo X, Wu Y, et al. Methylation profiling of 48 candidate genes in tumor and matched normal tissues from breast cancer patients. Breast Cancer Res Treat. 2015;149(3):767-779. 
80. Courtwright A, Siamakpour-Reihani S, Arbiser JL, et al. Secreted frizzle-related protein 2 stimulates angiogenesis via a calcineurin/ NFAT signaling pathway. Cancer Res. 2009;69(11):4621-4628.

81. Bhati R, Patterson C, Livasy CA, et al. Molecular characterization of human breast tumor vascular cells. Am J Pathol. 2008;172(5): 1381-1390.

82. Fontenot E, Rossi E, Mumper R, et al. A novel monoclonal antibody to secreted frizzled-related protein 2 inhibits tumor growth. Mol Cancer Ther. 2013;12(5):685-695.

83. Hsieh JC, Kodjabachian L, Rebbert ML, et al. A new secreted protein that binds to Wnt proteins and inhibits their activities. Nature. 1999; 398(6726):431-436.

84. Alvarez C, Tapia T, Cornejo V, et al. Silencing of tumor suppressor genes RASSF1A, SLIT2, and WIF1 by promoter hypermethylation in hereditary breast cancer. Mol Carcinog. 2013;52(6):475-487.

85. Trifa F, Karray-Chouayekh S, Jmal E, et al. Loss of WIF-1 and Wnt5a expression is related to aggressiveness of sporadic breast cancer in Tunisian patients. Tumor Biol. 2013;34(3):1625-1633.
86. Cai J, Guan H, Fang L, et al. MicroRNA-374a activates Wnt/betacatenin signaling to promote breast cancer metastasis. J Clin Invest. 2013;123(2):566-579.

87. Damalas A, Kahan S, Shtutman M, Ben-Ze'ev A, Oren M. Deregulated beta-catenin induces a p53- and ARF-dependent growth arrest and cooperates with Ras in transformation. EMBO J. 2001;20(17): 4912-4922.

88. Nakamura Y, de Paiva Alves E, Veenstra GJ, Hoppler S. Tissue- and stage-specific Wnt target gene expression is controlled subsequent to beta-catenin recruitment to cis-regulatory modules. Development. 2016;143(11):1914-1925.

89. Guo L, Yilamu D, Sun L, Liu S, Ma F. Association among the expression of beta-catenin, cyclin D1 and estrogen receptor-beta in human breast cancer. Exp Ther Med. 2015;10(4):1423-1428.

\section{Publish your work in this journal}

OncoTargets and Therapy is an international, peer-reviewed, open access journal focusing on the pathological basis of all cancers, potential targets for therapy and treatment protocols employed to improve the management of cancer patients. The journal also focuses on the impact of management programs and new therapeutic agents and protocols on

\section{Dovepress}

patient perspectives such as quality of life, adherence and satisfaction. The manuscript management system is completely online and includes a very quick and fair peer-review system, which is all easy to use. Visit http://www.dovepress.com/testimonials.php to read real quotes from published authors. 